\title{
A habitação do professor primário em meio rural durante a I República Portuguesa (1910-1926): análise de projetos de escolas e residências ${ }^{1}$
}

Primary school teacher's housing in rural environment during the First Portuguese Republic (1910-1926): analysis of school projects and residences

La vivienda del maestro de educación primaria en el medio rural durante la Primera República Portuguesa (1910-1926): análisis de proyectos de escuelas y residencias.

Carlos Manique da Silva

Universidade de Lisboa (Portugal)

https://orcid.org/0000-0003-4210-0723

manique@net.sapo.pt

\section{Resumo}

No presente artigo, assumo que o projeto integrador republicano procurou valorizar o papel social dos professores primários, nomeadamente, em meio rural, atribuindo-lhes (ou, pelo menos, pretendendo atribuir-lhes) determinadas condições para o desenvolvimento da sua missão. Uma dessas condições teve que ver com a habitação destinada ao professor. Adotando a perspetiva analítica definida por Viñao (2004), tento perceber a importância que a habitação do professor tem em alguns projetos de escolas e residências autónomas desenhados pelo arquiteto Raul Lino durante a I República (1910-1926). Concluo que a sobrevalorização desse espaço, manifestada no desenho, não encontra correspondente tradução prática; evidencio, assim, os limites do projeto reformista republicano, particularmente nos meios rurais (onde eram expectáveis soluções urgentes).

Palavras-chave: Habitação do professor. Projetos de escolas primárias. I República Portuguesa (1910-1926). Raul Lino. Escola em meio rural.

\footnotetext{
${ }^{1}$ Este trabalho é financiado por fundos nacionais através da FCT - Fundação para a Ciência e a Tecnologia, I.P., e cofinanciado pelo Fundo Europeu de Desenvolvimento Regional (FEDER) através do COMPETE 2020 e do Lisboa2020 no âmbito do "Projeto n. ${ }^{\circ} 029091$ MRIR-Memórias Resgatadas, Identidades Reconstruídas".
} 


\begin{abstract}
In this article, I assume that the republican integrating project seeks to enhance the social role of primary school teachers, namely, in rural areas, assigns them (or, at least, intends to assign them) the conditions for the development of their task. One of these conditions had to do with housing for the teacher. Adopting the analytical perspective defined by Viñao (2004), I try to understand the importance that the teacher's house has in some projects of schools and autonomous residences designed by the architect Raul Lino during the First Portuguese Republic (1910-1926). It was concluded that the overvaluation of this space, showed at the drawing level, didn't find practical correspondence; thus, the limits of the republican reformist project are evident, particularly in rural environments (where urgent solutions were expected).
\end{abstract}

Keywords: Teacher's housing. Primary schools' projects; First Portuguese Republic (19101926). Raul Lino. School in rural environment.

\title{
Resumen
}

En el presente artículo, admito que el proyecto integrador republicano buscó valorizar el papel social de los maestros de educación primaria, con particularidad en el medio rural, asignándoles (o por lo menos, intentando asignarles) determinadas condiciones para el desarrollo de su misión. Una de las condiciones estaba relacionada con la vivienda destinada al profesor. Adoptando la perspectiva analítica definida por Viñao (2004), intento comprender la importancia que la vivienda del profesor tiene en algunos proyectos de escuelas y residencias autónomas diseñadas por el arquitecto Raul Lino durante la Primera República (1910-1926). Concluyo que la sobrevaloración de ese espacio, manifestada en el diseño, no halla su traducción práctica; evidencio, así, los límites del proyecto reformista republicano, especialmente en los medios rurales (donde eran presumibles soluciones urgentes).

Palabras clave: Residencia del profesor. Proyectos de escuelas primarias. Primera República (1910-1926). Raul Lino. Escuela en el medio rural. 


\section{Introdução}

A dicotomia casa do mestre/ escola influencia decisivamente a organização interna das escolas primárias até à primeira metade do século XX (SILVA, 2005). A expressão "casa da escola" traduz a dupla ideia de alojamento para o professor e de salas organizadas para receber os alunos às horas das lições. A este respeito, Brullet (1998) introduz o conceito de domesticidade, demonstrando que, na casa do professor, a sala destinada às aulas, em resultado de novas exigências pedagógicas, vai progressivamente tornar-se independente e agregar outros espaços.

Ora, desde 1866, ano em que são publicadas em Portugal as primeiras normas sobre construção de escolas primárias, que se regula a habitação destinada ao professor. Mais tarde, em 1917, nas "NORMAS TÉCNICAS, HIGIÉNICAS E PEDAGÓGICAS A QUE DEVEM SATISFAZER OS NOVOS EDIFÍCIOS ESCOLARES, DECRETO n. ${ }^{\circ}$ 2947, DE 20 DE JANEIRO DE 1917", define-se que, nos meios rurais, o professor terá (por via de regra) residência no edifício escolar; adverte-se, no entanto, que entre os dois espaços não poderá haver comunicação. Por um lado, receia-se que o professor descure as suas obrigações profissionais; por outro lado, valoriza-se a sua presença no edifício escolar como forma de identificação com a escola e, mesmo, como elemento de afirmação no seio das populações (sobretudo, nos meios rurais). É o significado social da escola e o seu sentido histórico de construção e transformação que estão aqui em agenda (MAGALHÃES, 2010).

Assumindo a especificidade da I República (1910-1926) como conjuntura históricopedagógica, interessa-me perceber de que forma o projeto integrador republicano ${ }^{2}$ procurou valorizar o papel social dos professores primários em meio rural, atribuindo-lhes condições para o desenvolvimento da sua missão. Uma dessas condições prende-se, justamente, com a habitação destinada ao professor. A perspetiva analítica adotada incide sobre legislação (normas de construção de escolas primárias) e projetos de edifícios escolares com habitação para o professor (também alguns projetos autónomos de residências) desenhados pelo arquiteto Raul Lino (1879-1974). No caso dos referidos projetos, seguindo a investigação de Antonio Viñao (2004), terei em especial atenção: i) as dimensões relativas da escola/ habitação; ii) a articulação/ ligação entre ambas (a existir); iii) a especialização dos espaços da habitação (existência/inexistência de determinados espaços, a sua implantação interna, as suas dimensões). Para essa análise, acresce dizer, sigo um pressuposto formulado por Thomas Markus (1993): "functions of individual spaces could be understood because the relations between them were meaningful” (p. 29).

\section{Escola em meio rural}

Do que se fala quando se fala de escola em meio rural? Revejo-me na interpretação de A. Van Zanten; reporta-se este autor a uma escola de classe única numa pequena aldeia ou vila (por definição, "escola periférica") como tendo "une configuration scolaire spécifique du fait des caractéristiques de son publique, de certains traits de son fonctionnement interne et des relations qu'elle entretient avec le centre" (citado por JEAN, 2007, p. 8). ${ }^{3}$ Historicamente, essas caraterísticas são postas em evidência a partir da segunda metade do século XIX, momento de consolidação da escola graduada, segmentada por cursos e por idades (SILVA, 2008). É nítida, por exemplo, a clivagem entre docentes que lecionam nas escolas de classe única (situadas, na

\footnotetext{
${ }^{2}$ A noção aqui presente é a de que a República precisava de superar a utopia e olhar a realidade, impondo-se, por isso, entrar também no mundo rural (reconhecê-lo), onde eram extremamente baixos os índices de escolarização (AFONSO, 2016).

${ }^{3}$ Uma das caraterísticas específicas é, certamente, a heterogeneidade de idades e de níveis de aprendizagem dos alunos. Acresce, por exemplo, a pequena escala e a proximidade (CANÁRIO, 2008).
} 
sua maioria, em meio rural) e os seus homólogos das escolas graduadas (implantadas nas cidades). ${ }^{4}$ De resto, Aida Terrón e José María Rosada (2005) exploram bem esta dicotomia (escola urbana/escola em meio rural), ao estabelecerem uma diferenciação clara entre: cultura escolar, cuja origem entendem ser urbana; e cultura de contexto, aquela em que, segundo os mencionados autores, submergem os alunos antes de entrar e depois de sair do espaço cultural próprio da escola. ${ }^{5}$ Nesse sentido, para Aida Terrón e José María Rosada (2005), falar de escola em meio rural significa reportar duas culturas que evolucionam em sentido oposto. Mais explicitamente, o triunfo de uma implica o fim de outra:

La escuela se constituyó como un dispositivo institucional y organizativo especialmente destinado al modelamiento sistemático de la conducta infantil. Tuvo un origen urbano para atender a la demanda de unos saberes elementales, pero posteriormente se extendió a todos los ámbitos, penetrando en el medio rural sobre todo a partir de mediado del siglo XIX. En él la escuela contrastaba con la grande fuerza que tenía la cultura rural tradicional, en la que el niño vivía totalmente inmerso antes de entrar y después de salir de la escuela. Pero poco a poco la escuela se va asentando y adquiriendo fortaleza frente a la cultura rural [...] Así, paulatinamente, la escuela colabora como un factor más en la transformación del mundo rural, cuyos principios tradicionales se van viniendo debajo de forma acelerada en los últimos tiempos. (TERRÓN \& ROSADA, 2005, s.p.).

Durante anos, a escola em meio rural esteve muito entrosada com a comunidade. Concorreu para isso, entre outros fatores, a fraca mobilidade das populações rurais. Uma ligação que resultava também do facto de o poder local ter atribuições várias na dotação do ensino primário, nomeadamente, no que respeitava aos edifícios e mobiliário escolares, à habitação dos docentes, bem como no capítulo das caixas escolares.

Porém, há um paradoxo que acompanha a escola em meio rural desde, pelo menos, os anos de 1990, justamente quando esta começa a ser valorizada (CANÁRIO, 2008). ${ }^{6}$ Por um lado, a escola é vista como obsoleta e herdeira de uma organização pedagógica do século XIX; e, por outro lado, é considerada uma escola de futuro que interessa ao sistema educativo e, mesmo, à reconstrução identitária das comunidades rurais (JEAN, 2007; AMIGUINHO, 2008). Yves Jean (2007) fala numa espécie de nostalgia por uma escola que muitas das gerações de hoje ainda conheceram, mas que está em vias de desaparecer; por oposição a uma escola urbana, frequentemente sobrecarregada de alunos (JEAN, 2007). Mas, obviamente, o que está em causa é próprio futuro do mundo rural (CANÁRIO, 2008).

\section{A I República e o reconhecimento do mundo rural}

Para o ativismo político republicano, uma das questões fundamentais era a que se prendia com o analfabetismo (PINTASSILGO, 2010). Não menos verdadeiro será afirmar que a I República reconheceu e quis dar corpo a um projeto que abrangesse o mundo rural (AFONSO,

\footnotetext{
${ }^{4}$ Essa clivagem é, aliás, marcante no município de Lisboa nos anos de 1880, com os docentes das escolas de classe única (designadas paroquiais) a manifestarem a sua condição de inferioridade relativamente aos seus colegas das escolas graduadas (designadas centrais). No fundamental, tal sentimento tinha que ver com a dificuldade pedagógica de lidar com alunos de diferentes níveis cognitivos (SILVA, 2008).

${ }^{5}$ Um autor como Abílio Amiguinho (2008) fala em confronto entre cultura escolar e cultura local.

${ }^{6}$ Em Portugal, no ano de 1994, teve início um projeto de intervenção educativa no mundo rural, designado "Projeto das escolas rurais" (CANÁRIO, 2008).
} 
2016), formalizando, para o efeito, as chamadas escolas móveis. Não se tratava, no entanto, de desenvolvimento "do rural como rural", para utilizar a expressão de Justino Magalhães (2016, p. 9). Tratava-se, sim, lembrando a perspetiva avançada por Terrón \& Rosada (2005), da afirmação da escola enquanto instituição, se preferirmos, de um projeto cultural de nacionalização que implicava a sobreposição da cultura urbana à cultura rural. Aliás, os relatos coetâneos deixam perceber não só a subestimação dos modos de socialização e de formação das crianças que vivem em meio rural, como também a própria visão "da ruralidade como antípoda da modernidade" (AFONSO, 2016, p. 38). E no Portugal da I República a presença da escola é ainda muito débil. Todas estas aceções são bem elucidadas por Abílio David, professor de História que, por vicissitudes várias, exerceu funções docentes numa escola móvel do distrito de Leiria:

Esta missão poderia dar muito mais porque, não obstante tratar-se de uma terra redondamente analfabeta, o certo é que os seus habitantes têm ânsia de saber. É um povo absolutamente ignorante, no rigoroso sentido da expressão.

Está a 15 quilómetros de uma cidade civilizada e capital de distrito [Leiria]. Pois a cada hora eu tenho a noção concreta, positiva, iniludível, de que estou a 1500 quilómetros de uma cidade civilizada!

É um povo de bárbaros! (DAVID, 1916, pp. 144-145).

A própria geografia das escolas móveis denuncia a vontade política do Estado escolarizar crianças em meio rural. E também procurou marcar presença no território nacional através da construção de escolas, embora, deva dizer-se, de forma inconsequente. De facto, em 1918, respondendo, certamente, a uma encomenda oficial, Raul Lino desenhou um projeto regionalizado de escola primária prevendo três versões, consoante se destinassem ao norte, ao centro ou ao sul do país (SILVA, 2011). Porém, tal projeto nunca chegou a ser concretizado; serviu, no entanto, de ensaio para os projetos regionalizados aprovados em 1935 para as regiões do Algarve, Estremadura, Alentejo e Ribatejo (efetivamente concretizados). ${ }^{7}$

A descoberta do país rural far-se-á, sobretudo, pelo confronto com "inúmeras resistências [...] dependentes de um quotidiano matriciado num tempo distinto" (AFONSO, 2016, p. 77). A este respeito, os professores das escolas móveis terão contacto privilegiado com as realidades locais, algo que lhes permitirá conhecer as limitações das populações (particularmente, das rurais); em causa, dir-se-ia, a (im)possibilidade de construção de uma nova cidadania, se preferirmos, de uma sociedade liberal. São, certamente, elucidativos os relatos do já citado professor Abílio David (1916). Veja-se, por exemplo, o caso de um aluno que se dirigiu ao professor nos seguintes termos: "O meu pai manda dizer que me dê a lição e que me mande embora, que tenho de ir com os bois" (DAVID, 1916, p. 148). Não surpreende, pois, face a muitos outros casos que apresenta, o seguinte comentário: "todos, em absoluto todos, exploram infamemente o trabalho dos menores” (DAVID, 1916, p. 150).

À luz do que foi sendo referido compreende-se a importância que a I República atribuiu, lato sensu, à missão do professorado primário (Nóvoa, 1988); por maioria de razão, àqueles que lecionavam nos meios rurais. As citadas "NORMAS TÉCNICAS, HIGIÉNICAS E PEDAGÓGICAS A QUE DEVEM SATISFAZER OS NOVOS EDIFÍCIOS ESCOLARES, 1917" sublinham essa distinção, isto é, reconhecem a especificidade do papel/ presença do professor em meio rural.

\footnotetext{
${ }^{7}$ A inconsequência da política educativa neste capítulo é, de facto, assinalável. Tome-se como referência o Decreto n. ${ }^{\circ} 4642$, de 14 de julho de 1918, o qual autorizava o governo a contrair um empréstimo com a Caixa Geral de Depósitos tendo em vista a criação de escolas primárias com cantinas em todo o país.
} 


\section{Reconhecimento identitário das escolas: a dicotomia urbano/rural}

Na sua obra Les constructions scolaires en Suisse (1907), o arquiteto genebrino Henri Baudin (1876-1929) refere que, sob a aparente uniformidade de programas e regulamentos, o edifício escolar é uma obra com caráter pessoal (leia-se, única). Do seu ponto de vista, vários itens concorrem para essa condição, a saber: i) o destino/ função (escola primária, secundária...); ii) aquilo que designa por "dispositions générales" (escola de raparigas ou de rapazes, mista); iii) o meio (aldeia, vila, cidade, cantão); iv) a utilização de materiais locais (BAUDIN, 1907, p. 109). Segundo indica ainda, o próprio aspeto estético, frequentemente relacionado com o contexto local, é fator de especificidade (BAUDIN, 1907).

Para a minha agenda de investigação, importa afirmar que o arquiteto suíço estabelece distinção entre edifícios de escolas urbanas e de escolas rurais (a terminologia é sua). Por exemplo, ao enunciar as caraterísticas das escolas primárias modernas, deixa patente que apenas as escolas rurais têm habitação para o(s) docente(s). Aliás, é muito interessante que a referida distinção tenha que ver, em larga medida, com a adaptação ao meio. Com efeito, Baudin (1907) relata que à medida que aumenta a altitude das localidades montanhosas, mais o edifício escolar se simplifica, tornando-se modesto e adequado aos rigores do clima.

Figura 1. Escola de montanha (Suíça).

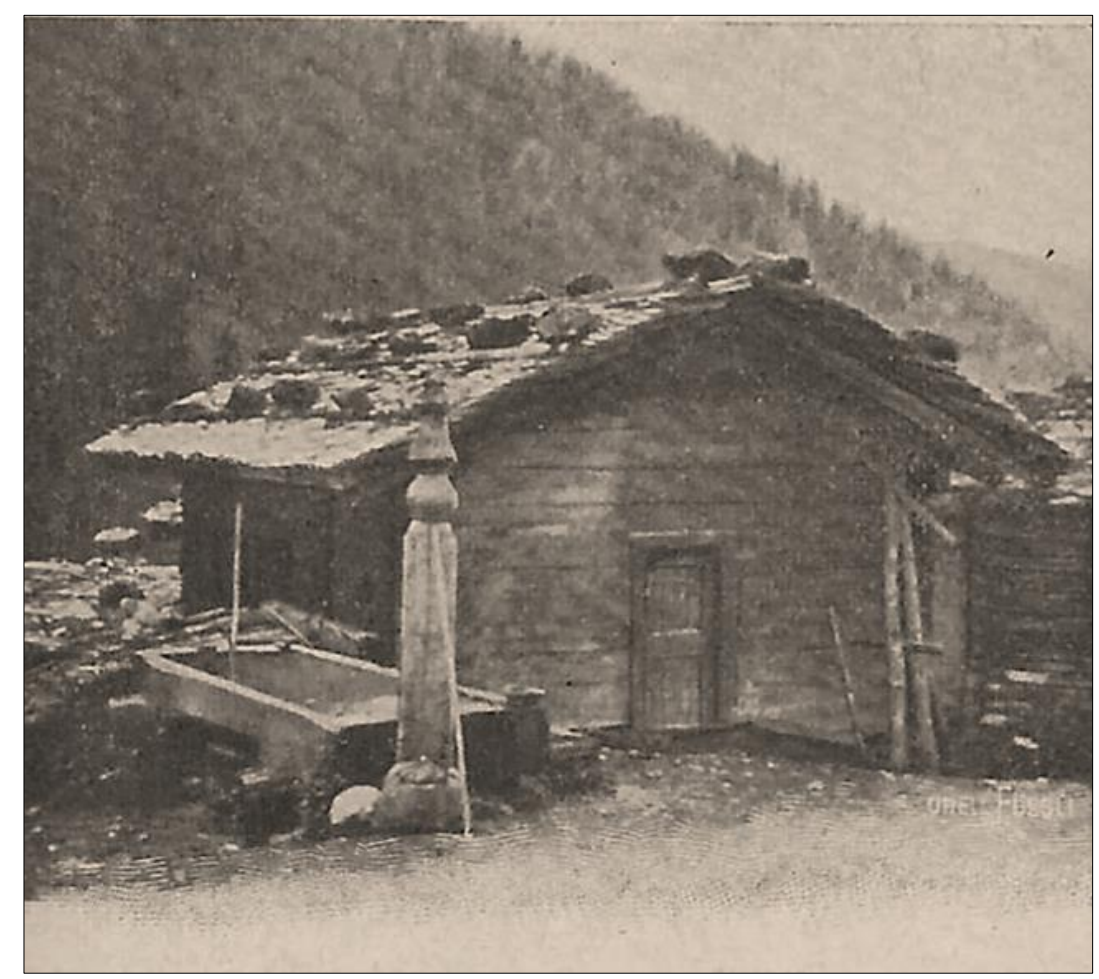

Fonte: BAUDIN (1907).

A tipificação do edifício da escola rural está bem presente na obra do arquiteto M. A. Audrey, que desenvolveu atividade profissional no cantão suíço de Friburgo (BAUDIN, 1907). Efetivamente, a análise de alguns projetos de escolas primárias rurais de sua autoria deixa perceber as seguintes caraterísticas comuns: i) existência de poucas classes (entre uma a três); ii) fachadas muito simples e sóbrias; iii) habitação para um ou mais professores no último piso do edifício da escola (cf. BAUDIN, 1907).

Em Portugal, a dicotomia urbano/rural é percetível em projetos de edifícios para escolas primárias desde, pelo menos, meados do século XIX. Por exemplo, em 1864, o inspetor Mariano Ghira divulgou, justamente, um conjunto de projetos que evidenciavam a referida distinção 
(SILVA, 2005). Não se estranha, se tivermos em linha de conta que, em meados do referido século, só $11 \%$ da população vivia em centros urbanos; e em 1890 esta cifra não ia além dos $15 \%$ (BONIFÁCIO, 2005). Atente-se, agora, aos seguintes projetos promovidos por Mariano Ghira.

Figura 2. Modelo de escola primária para as cidades.

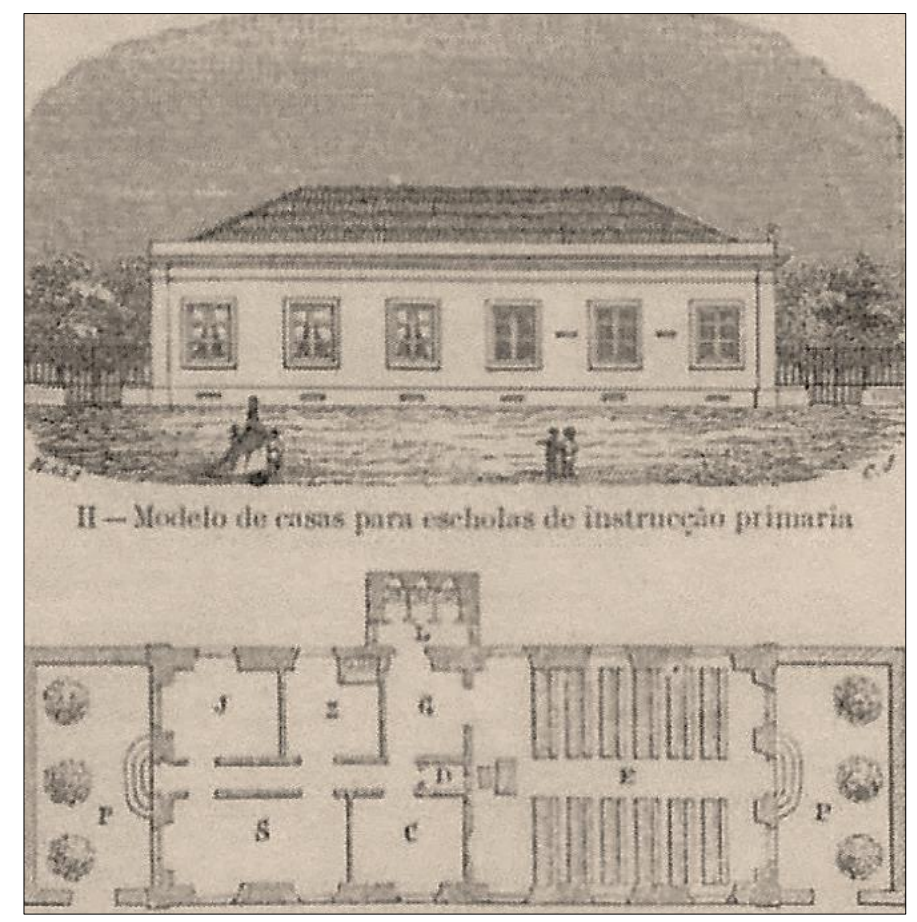

Fonte: GHIRA (1864).

Figura 3. Modelo de escola de primária para as freguesias rurais.

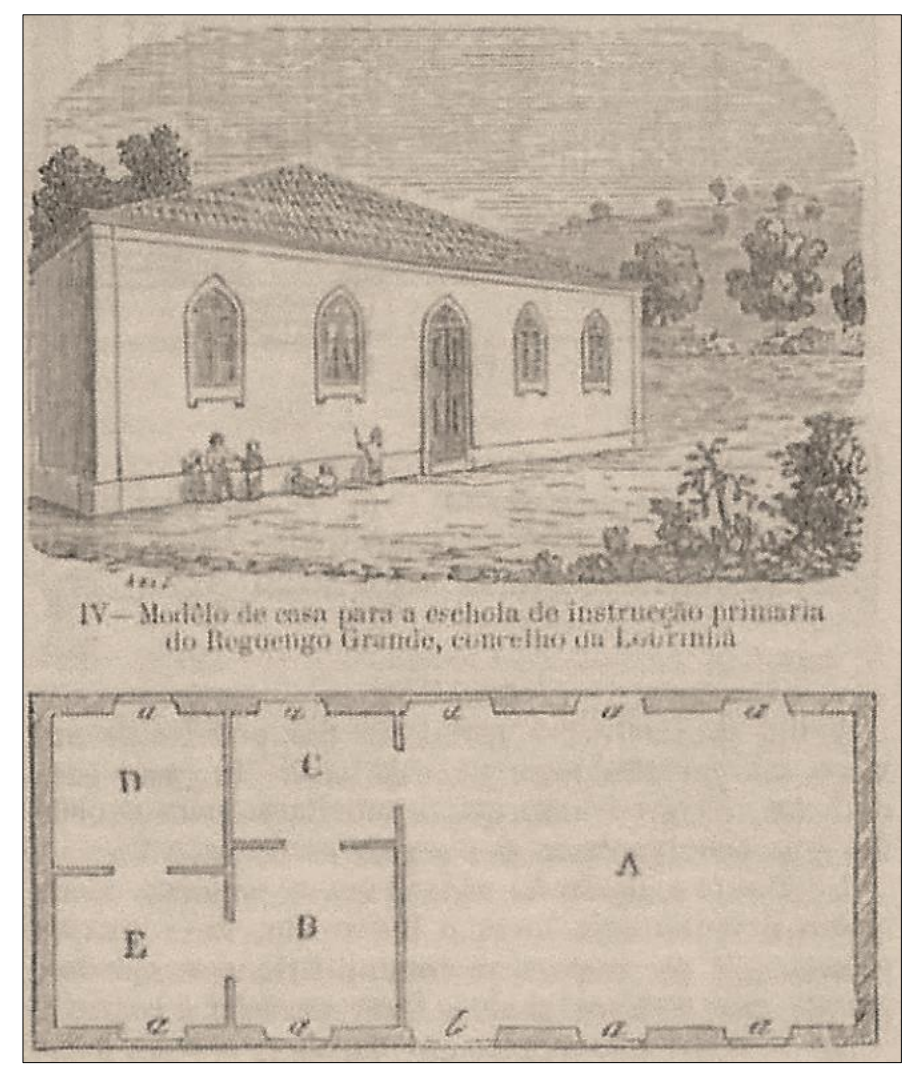

Fonte: GHIRA (1864). 
No que respeita ao modelo destinado às cidades, assinale-se a existência de um pequeno terreno arborizado na zona adjacente às entradas para a escola e residência do professor subliminar presença da natureza. Pelo contrário, o modelo de escola destinado às zonas rurais evidencia harmoniosa integração no ambiente natural. Mais, o prospeto de edifício de escola para as cidades contrasta com a simplicidade do destinado aos meios rurais. No primeiro caso, é evidente a necessidade de afirmação da escola como locus público de educação e território de poder, seja pelo caráter mais distinto do edifício, seja também pela imposição de barreiras físicas através de gradeamentos, "qui interdit de considérer une école comme un espace publique, même si c'est une institution publique", para seguir à letra Perrenoud (2001, s. p.).

Em ambas as situações se contempla, no próprio edifício, com relevante área e comunicando internamente com a escola, habitação para o docente. $\mathrm{O}$ primeiro conjunto de normas para edificação de escolas primárias (PORTARIA DE 20 DE JULHO DE 1866) vai consagrar a existência de habitação para o professor, mas separada do edifício da escola. Veja-se o seguinte conjunto de argumentos:

Tendo o professor residência num edifício público fica aliviado de um encargo e de um cuidado, prende-se mais à escola, identifica-se com ela e dedica-se com mais gosto à sua laboriosa profissão. A vivenda dos mestres é, pois, um útil acessório à escola. Esta residência, em regra, deve ser separada, mas não distante da escola, para que o professor possa vigiar a entrada dos alunos. (PORTARIA DE 20 DE JULHO DE 1866, artigo 46. ${ }^{\circ}$ ).

No decurso da I República essas orientações mudam significativamente. Com efeito, nas "NORMAS TÉCNICAS, HIGIÉNICAS E PEDAGÓGICAS..., 1917", sustenta-se que o professor terá residência no próprio edifício da escola, não podendo, porém, haver comunicação interna entre ambos os espaços; disposições que se referem apenas às povoações rurais e na circunstância de não ser "fácil encontrar alojamento para o professor" ("NORMAS TÉCNICAS, HIGIÉNICAS E PEDAGÓGICAS..., 1917”). Mas, o normativo vai mais longe, ao estabelecer que a residência do professor deve ter, pelo menos, as seguintes divisões: gabinete de estudo, sala de jantar, três quartos, cozinha e instalações sanitárias. Esta última especificação dá bem a noção da importância que a I República atribuiu ao professor primário (particularmente, em meio rural), considerado "árbitro dos destinos morais da Pátria".

\section{A habitação do professor em alguns projetos desenhados por Raul Lino}

Raul Lino foi, porventura, um dos arquitetos que mais edifícios escolares projetou em Portugal (escolas infantis, escolas primárias, liceus e escolas profissionais). Durante a I República desenhou vários projetos que não tiveram consequência prática (SILVA, 2011). Exceção de referência são, certamente, os Jardins-Escolas João de Deus (Coimbra, 1911; Alcobaça, 1914; Lisboa, 1917...), que continuariam, aliás, a ser construídos durante o período do Estado Novo, segundo a mesma planta.

Não obstante o referido, julgo importante analisar um conjunto de projetos de escolas primárias com habitação para professor e, mesmo, uma proposta de residências autónomas, concebidos por Raul Lino entre 1916 e 1922; os quais, de facto, não passaram da fase de desenho. A análise das respetivas plantas segue a metodologia definida por Viñao (2004), a qual, no essencial, considera: i) a especialização dos espaços e as suas dimensões relativas; ii) a relação/ articulação entre diferentes espaços funcionais.

\footnotetext{
${ }^{8}$ REFORMA REPUBLICANA DO ENSINO INFANTIL, PRIMÁRIO E NORMAL, DECRETO DE 29 de MARÇO DE 1911.
} 
O primeiro projeto a analisar foi desenhado em 1916 (Figura 4); é anterior, portanto, à publicação das “NORMAS TÉCNICAS, HIGIÉNICAS E PEDAGÓGICAS..., 1917”. Trata-se de um edifício escolar com quatro salas (aulas comuns, tudo leva a crer) e residência para um professor (na planta, situada à direita do observador). Um dos aspetos que interessa referir tem que ver com a ligação entre espaço destinado ao trabalho e espaço reservado à habitação. Thomas Markus (1993) elucida bem esta questão. Com efeito, a sua argumentação deixa perceber que, até ao século XVIII, "work and living space often being hard to distinguish" (MARKUS, 1993, p. 284). Segundo refere o mesmo autor, o "tipo" arquitetural mais universal é o da quinta, no qual o espaço da habitação está combinado com o espaço destinado aos animais, ferramentas, forragens... A separação entre as duas esferas começa a surgir em alguns projetos utópicos da primeira metade de Oitocentos, designadamente, em New Lanark (Escócia), quando Robert Owen se afasta das realidades da produção e começa a concentrar os seus esforços no alojamento e no projeto educativo (MARKUS, 1993).

Figura 4. "Projeto para um edifício escolar", Raul Lino, 1916.

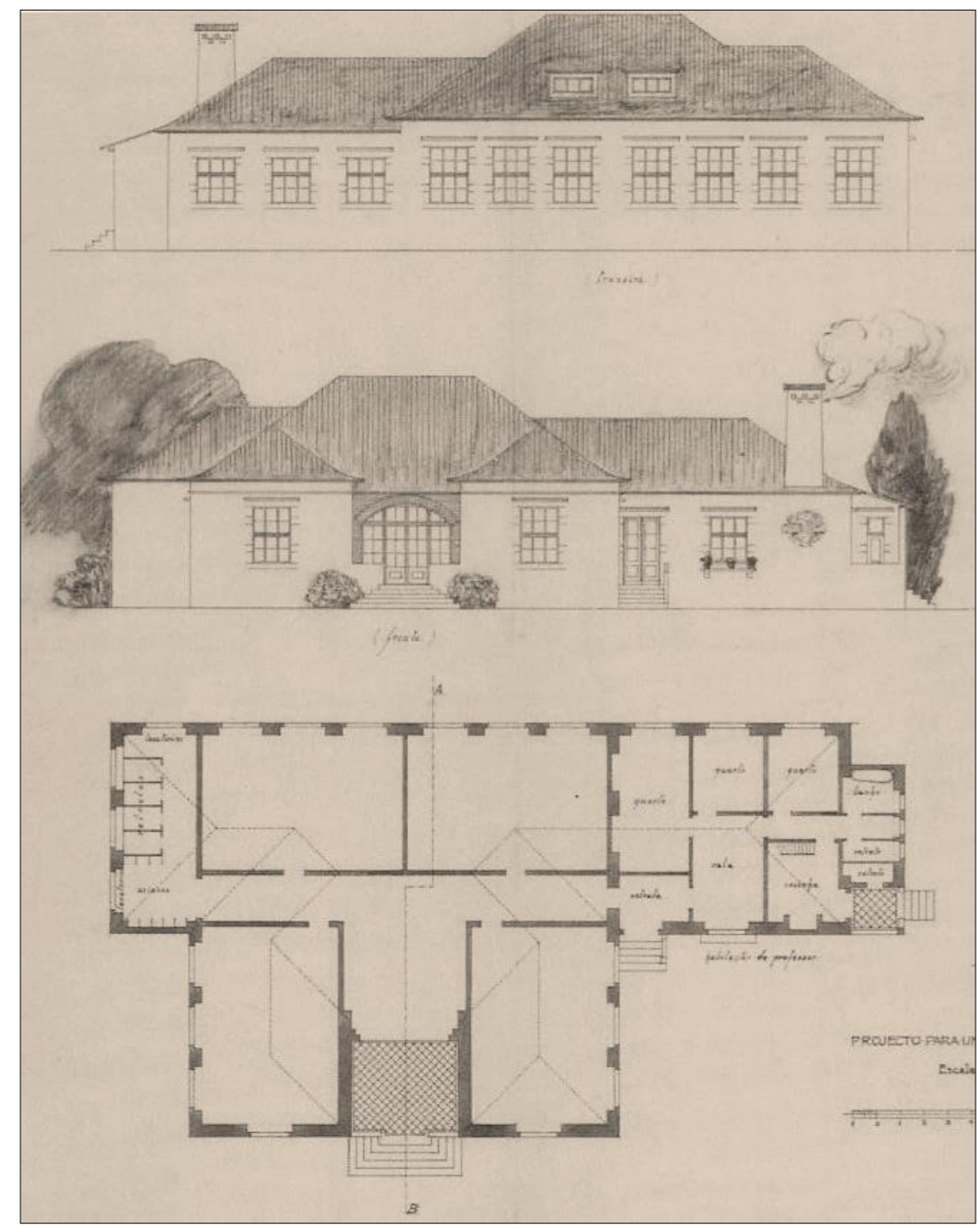

Fonte: Fundação Calouste Gulbenkian, Espólio Raul Lino. 
No caso do edifício escolar projetado por Raul Lino é inextricável a ligação de que fala Thomas Markus. Veja-se, por exemplo, que existe comunicação interna entre a habitação do professor (que ocupa cerca de 1/5 da área total do edifício) e a escola; algo que, recordo, será proibido nas "NORMAS TÉCNICAS, HIGIÉNICAS E PEDAGÓGICAS..., 1917". Por outro lado, a habitação não consagra um espaço reservado destinado a estudo/ trabalho (gabinete), conforme será preconizado no normativo de 1917. Efetivamente, além de quartos (em número de três), sala, cozinha e instalações sanitárias, não são diferenciados quaisquer outros espaços; a elevada permeabilidade entre as duas esferas (habitação e local de trabalho) poderá ajudar a explicar a ausência de um gabinete ou escritório. A mesma situação se observa num projeto de edifício escolar com oito salas e residência para um professor (Figura 5).

Figura 5. "Projeto de um edifício escolar", 1. p pavimento, Raul Lino, 1916.

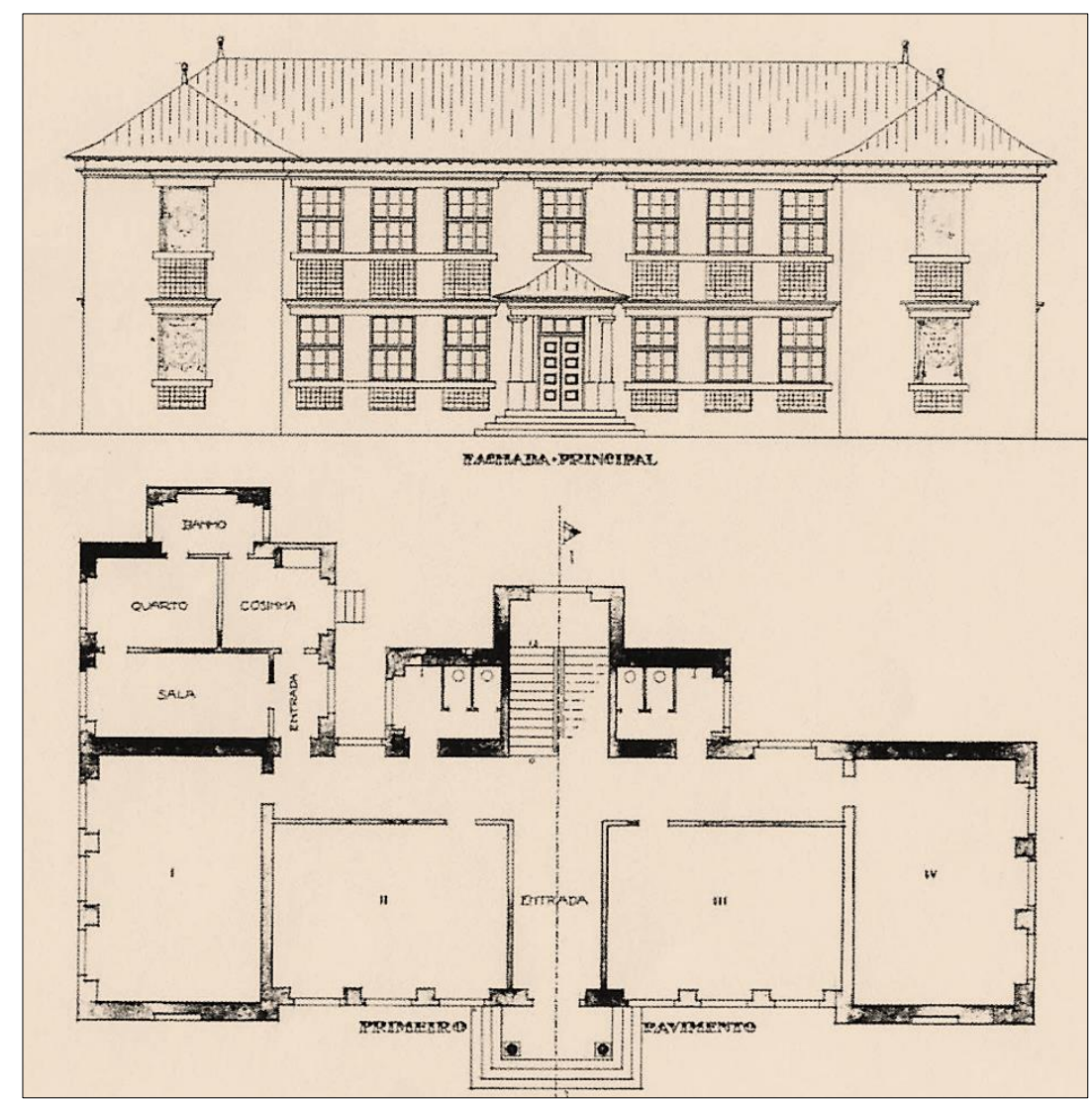

Fonte: Fundação Calouste Gulbenkian, Espólio Raul Lino.

Volvidos cinco anos, Raul Lino desenhou um conjunto de projetos intitulado "Casas de habitação para professores", segundo os seguintes tipos regionalizados: "Norte", "Central", "Ribatejano", "Serrano" e "Queluz". Tratou-se, tudo leva a crer, de uma encomenda oficial. A ideia era garantir habitação - em edifício próprio muito condigno e independente da escola aos professores primários que trabalhassem em meio rural (a esmagadora maioria, portanto). Os quatro primeiros projetos indicados seguem a mesma planta, desenvolvida em dois pisos (Figura 6). De facto, alterações só mesmo no exterior, sobretudo, no capítulo decorativo e em função dos recursos naturais da região. 
Figura 6. "Casas de habitação para professores”, Raul Lino, 1921.

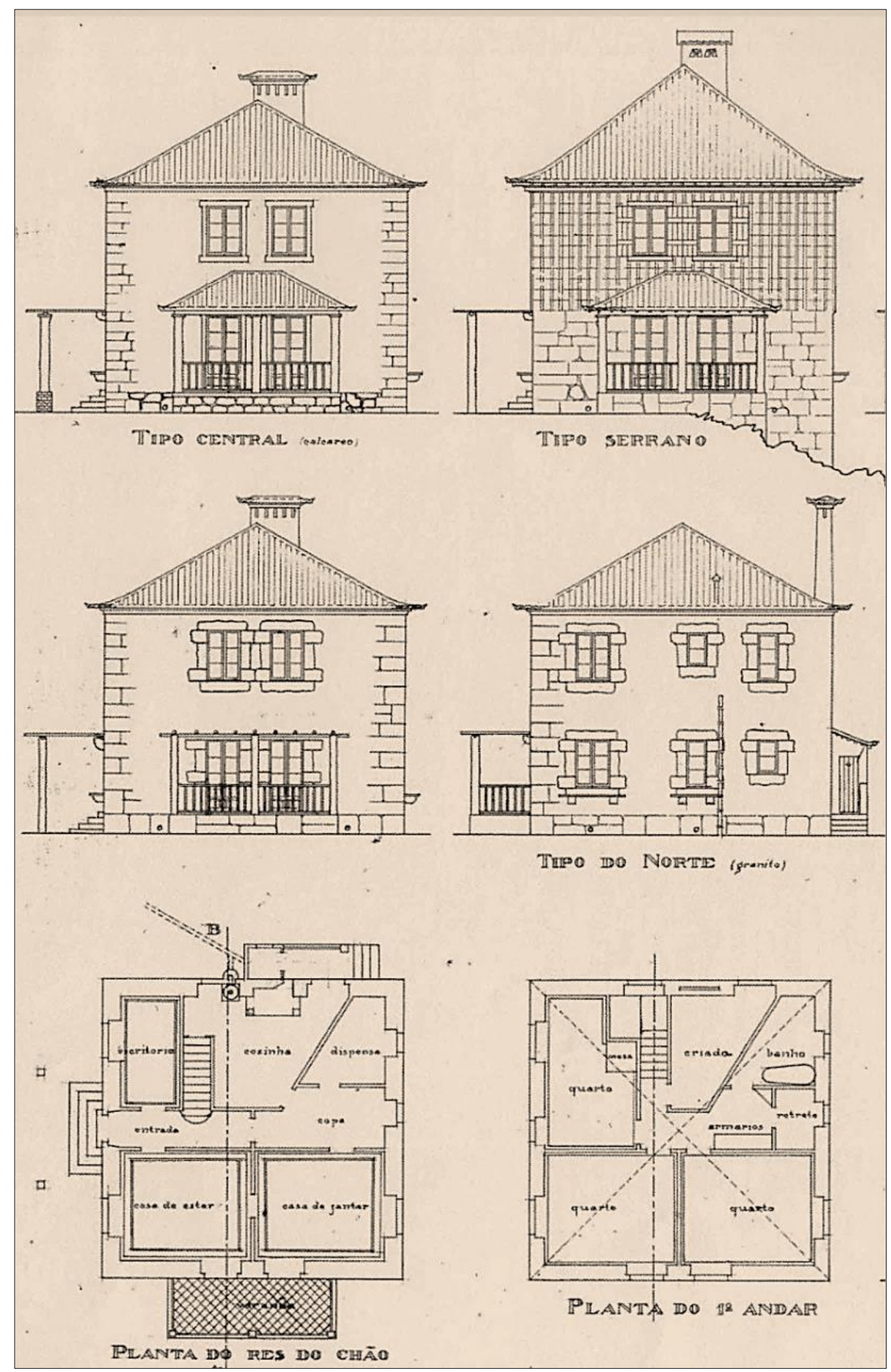

Fonte: Fundação Calouste Gulbenkian, Espólio Raul Lino.

Nota: Na figura não surge representado o alçado do projeto tipo "Ribatejano". 
Por outro lado, o projeto tipo "Queluz" apresenta apenas um piso. Porém, em todos eles se assiste à mesma especialização dos espaços, em linha, aliás, com as "NORMAS TÉCNICAS, HIGIÉNICAS E PEDAGÓGICAS..., 1917”.

Figura 7. “Casas de habitação para professores”, Raul Lino, 1921.

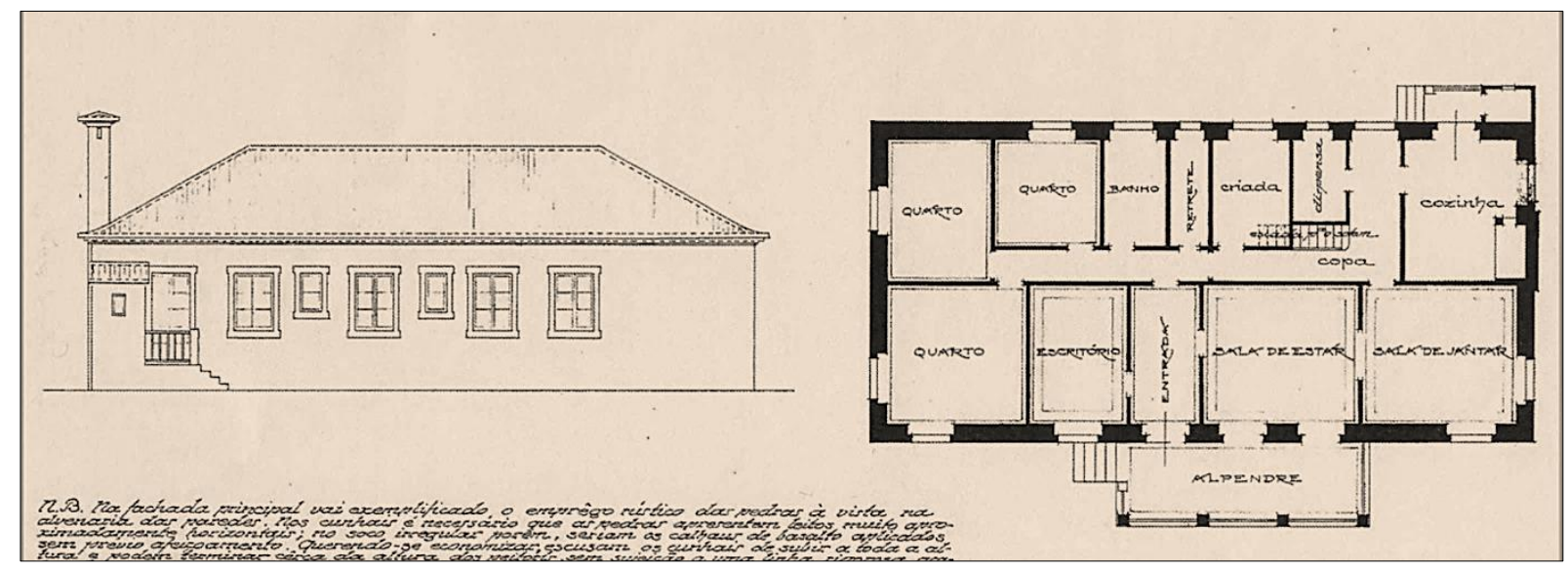

Fonte: Fundação Calouste Gulbenkian, Espólio Raul Lino.

Considerando a planta reproduzida na Figura 7, é clara a divisão entre a área mais reservada da habitação (quartos) e a área social da mesma (sala de estar e sala de jantar). E não deixa de ser simbólica a localização do escritório, ou seja, junto à entrada, em frente à sala de estar ${ }^{9}$ e, ao mesmo tempo, dando para a fachada principal; implantação que, em meu entender, procura valorizar o trabalho (intelectual) do professor e afirmar o seu estatuto social no seio da comunidade.

A comparação da planta do projeto tipo "Queluz" com as plantas dos projetos tipo "Norte", "Central", "Ribatejano" e "Serrano" (estas quatro últimas idênticas, conforme afirmei) reforça a ideia expressa no parágrafo anterior, isto é, o pretendido efeito simbólico da localização do escritório. Com efeito, e atente-se novamente à Figura 6, foi opção do arquiteto Raul Lino manter o escritório junto à entrada (piso térreo), em frente à sala de estar e voltado para a fachada principal. A intenção de conferir alguma visibilidade pública a esse espaço sobrepôs-se à possibilidade de o implantar num local mais reservado, por exemplo, no $1 .^{\circ}$ andar (apenas destinado aos quartos).

Uma última nota a respeito destes projetos regionalizados, para sublinhar, uma vez mais, a importância que a I República atribuiu ao professor de instrução primária (consequentemente, à valorização do seu estatuto social). Com efeito, em todos eles está previsto um espaço autónomo para alojamento da criada.

\footnotetext{
${ }^{9}$ Creio que a implantação do escritório em relação à sala de estar (frente a frente) está associada ao relacionamento institucional com o exterior. Na verdade, entre outras funções, o último espaço funcionaria como antecâmara do primeiro, no qual o professor, além de trabalhar, poderia receber familiares dos alunos. Veja-se, ainda, que o escritório não tem comunicação direta com os quartos; a sua entrada está situada muito perto da entrada principal do edifício.
} 
Figura 8. "Projeto de uma escola com habitação para professor no concelho da Figueira da Foz", Raul Lino, 1922.
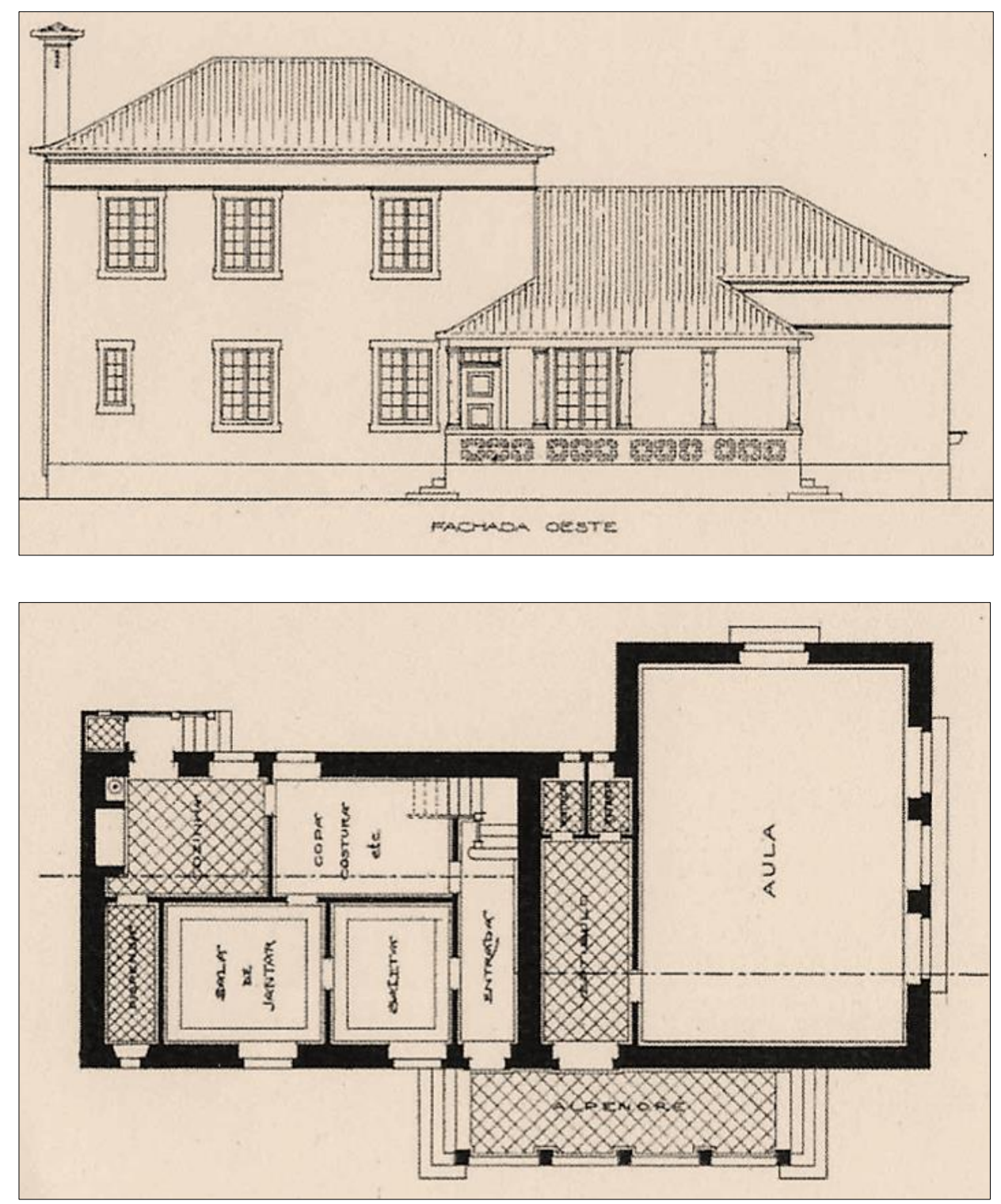

Fonte: Fundação Calouste Gulbenkian, Espólio Raul Lino.

Encerro com algumas observações sobre um projeto de escola com habitação para professor, datado de 1922 (Figura 8). A habitação, cuja planta se desenvolve em dois pisos, recebe bastante destaque. Na verdade, a sua área é superior à do espaço escolar (circunscrito, praticamente, à sala de aula). Atendendo às "NORMAS TÉCNICAS, HIGIÉNICAS E PEDAGÓGICAS..., 1917”, Raul Lino, ao contrário do que sucedera com os projetos desenhados antes da citada regulação (Figuras 4 e 5), integra o princípio da não comunicação interna entre ambos os espaços (escola e habitação). Os quartos estão localizados no $2{ }^{\circ}$ piso. Por outro lado, não há referência direta a um espaço destinado a escritório ou gabinete. No entanto, no rés-do-chão, junto à entrada, o arquiteto projetou uma "saleta". É possível que tenha sido pensada como espaço multifuncional. 


\section{Considerações finais}

Conforme se afirmou, o projeto integrador republicano procurou valorizar o papel dos professores primários, designadamente, em meio rural. Na conjuntura histórica-pedagógica da I República, o intento de construir escolas com habitação para professor e, mesmo, residências autónomas enquadra-se, em larga medida, nesse desígnio. Recordo, aliás, que as "NORMAS TÉCNICAS, HIGIÉNICAS E PEDAGÓGICAS..., 1917” preveem apenas habitação para o docente que exerce o magistério em meio rural. No entanto, os programas oficiais - de escolas regionalizadas, em 1918, e de residências autónomas para professores, em 1921, também regionalizadas - não têm tradução prática. São, de resto, perfeitamente utópicos face às reais condições do país.

No que respeita, em específico, à habitação do professor, importa dizer que, nos projetos de escolas analisados, se assiste à sobrevalorização desse ambiente. Por outro lado, e particularmente no caso das residências autónomas, a especialização interna dos espaços faz eco da vontade de dignificar o professor primário junto da comunidade.

Seguindo as propostas analíticas de Markus (1993) e de Viñao (2004), a interpretação dos projetos teve em conta as funções dos espaços individuais e as relações entre eles. Mas é evidente que o desconhecimento das memórias descritivas dos projetos em causa impõe limites à leitura que propus.

Não obstante a inconsequência da generalidade das medidas tomadas no decurso da I República, e estou a cingir-me aos programas de construção de edifícios escolares, a verdade é que há uma ideação de futuro que traduz a vontade de alinhar o país com os sistemas educativos de referência, nomeadamente, europeus (SILVA, 2016). A utopia e a visão comparatista pautaram, de facto, o ideário educativo republicano.

\section{Referências}

AFONSO, José António. Escolas rurais na I República Portuguesa. 1910-1926. Discursos e representações sobre a periferia. Santo Tirso: Whitebooks, 2016.

AMIGUINHO, Abílio. Escola em meio rural: uma escola portadora de futuro? Educação, Santa Maria, v. 33, n. 1, p. 11-32, 2008.

BAUDIN, Henri. Les Constructions Scolaires en Suisse. Genebra: Editions d'Art et d'Architecture, 1907.

BONIFÁCIO, Fátima. O século XIX português. 2. ${ }^{a}$ edição. Lisboa: Imprensa de Ciências Sociais, 2005.

BRULLET, Manuel. L'arquitectura dels espais educatius. Temps d'Educació, Barcelona, n. 19, p. 23-34, 1998.

CANÁRIO, Rui. Escola rural: de objecto social a objecto de estudo. Educação, Santa Maria, v. 33, n. 1, p. 33-44, 2008. 
DAVID, Abílio. Escolas Móveis. Lisboa: Bibliotrónica Portuguesa, 2015 [texto de 1916].

GHIRA, Mariano. Casas para escolas. Archivo Pittoresco, Lisboa, v. VII, n. 21 e n. 26, p. 164166 e 207-208, 1864.

JEAN, Yves (dir.). Géographies de l'école rurale : acteurs, réseaux, territoires. Paris: Éditions Ophrys, 2007.

MAGAlHÃES, Justino. Prefácio. In Escolas rurais na I República Portuguesa. 1910-1926. Discursos e representações sobre a periferia, AFONSO, José António, 7-12. Santo Tirso: Whitebooks, 2016.

MAGALHÃES, Justino. Da cadeira ao banco. Escola e modernização (séculos XVIII-XX). Lisboa: Educa e UI \& DCE, 2010.

MARKUS, Thomas. Buildings and Power. Freedom and Control in the Origin of Modern Building Types. London and New York: Routledge, 1993.

"Normas Técnicas, Higiénicas e Pedagógicas a que devem satisfazer os novos edifícios escolares", Decreto n. ${ }^{\circ}$ 2947, de 20 de janeiro de 1917.

NÓVOA, António. A República e a Escola. Das intenções generosas ao desengano das realidades. Revista Portuguesa de Educação, Braga. v. 1, n. 3, p. 29-60, 1988.

PERRENOUD, Philippe. Espaces-temps de formation et organisation du travail, 2001. www.unige.ch/fapse/SSE/groups/life/seminaire/S06 texte 0711 2001.htm (acesso em 01/03/2020)

PINTASSILGO, Joaquim. A República e a educação: dos projetos às realizações. In José Mendes Cabeçadas Júnior e a Primeira República no Algarve, GUERREIRO, Luís M. Mendes \& GASPAR, Diogo (coord.), 182-191. Loulé: Câmara Municipal de Loulé, 2010.

Portaria de 20 de julho de 1866, Diário de Lisboa, n. 163.

SILVA, Carlos Manique da. A Primeira República Portuguesa Recria o Ministério da Instrução Pública: um esforço de aproximação aos sistemas escolares europeus. História da Educação, Santa Maria, v. 20, n. 50, p. 367-381, 2016. https://doi.org/10.1590/2236-3459/63180

SILVA, Carlos Manique. Projetos de escolas primárias do arquiteto Raul Lino durante a I República portuguesa. Revista Linhas, Florianópolis, v. 12, n. 1, p. 33-50, 2011.

SILVA, Carlos Manique da. Do modo de aprender e de ensinar. Renovação pedagógica e cenários de experimentação da escola graduada (1834-1892). Tese de Doutorado. Lisboa: Faculdade de Psicologia e de Ciências da Educação, 2008. 
SILVA, Carlos Manique da. Escolas belas ou espaços sãos? Uma análise histórica sobre a arquitetura escolar (1860-1920). Lisboa: IIE, 2002.

TERRÓN, Aida \& ROSADA, José María (2005). La escuela rural. In Los Asturianos. Raíces culturales y sociales de una identidade, RODRÍGUEZ MUÑOZ, J. (dir.), 546-560. Oviedo: Prensa Asturiana, 2005.

VIÑAO, Antonio. Espacios escolares, funciones y tareas: la ubicación de la dirección en la escuela graduada. Revista Española de Pedagogía, n. 228, p. 279-304, 2004. 